\title{
CASOS DE MASTITE SUBCLÍNICA EM VACAS LACTANTES DA RAÇA GIROLANDA NO PERÍODO SECO E CHUVOSO DO ANO, NA REGIÃo LITORAL DO RIO GRANDE DO NORTE
}

\author{
SILVA, Andrezza Miguel da ${ }^{1}$ \\ CAVALCANTI, Elizete Teresinha Santos ${ }^{2}$
}

Recebido em: 2011-09-21

Aprovado em: 2012-05-22

ISSUE DOI: $10.3738 / 1982.2278 .658$

\begin{abstract}
RESUMO: O objetivo deste trabalho foi avaliar o efeito dos diferentes períodos do ano, sobre a incidência de casos de mastite subclínica em vacas Girolanda, em uma fazenda na região Litoral do Rio Grande do Norte. Para isso, foi realizado o California Mastits Test, no leite das vacas multíparas e primíparas, durante a ordenha da manhã. O período de estudo foi durante os meses de novembro de 2005 a novembro de 2006 . Verificou-se que o período do ano afetou a ocorrência de casos de mastite subclínica nas vacas. Maior quantidade de casos da doença ocorreu no período chuvoso do ano, com valores de 59,8\% (tetos) e de $81,6 \%$ (animais).
\end{abstract}

Palavras chave: Bovinos. Leite. Incidência.

SUMMARY: The objective of this study was to evaluate the effect of different periods the year, on the incidence of subclinical mastitis in cows Girolanda, on a farm in the region Coastal of Rio Grande do Norte. For this, we performed the California Mastits Test in the milk of cows multiparous and primiparous during the milking morning. The period of study was during the months of November 2005 to November 2006. It was found that the period of the year affected the occurrence of cases of mastitis subclinical in cows. Larger number of cases of disease occurred during the rainy season of the year, with values of 59,8\% (teats) and $81,6 \%$ (animals).

Keywords: Cattle. Milk. Incidence.

\section{INTRODUÇÃO}

A produção de leite como qualquer outra atividade produtiva deve gerar lucro, de modo que, a cadeia produtiva seja sustentável. O lucro da atividade está em função da produtividade, dos custos de produção e do preço do leite. Diversas variáveis influenciam a produção de leite dos animais, entre elas a presença de mastite (COLDEBELLA, 2003).

Mastite é a denominação do processo inflamatório da glândula mamária (FREITAS et al, 2005) resultado final da interação entre diferentes fatores, incluindo: a resistência natural ou susceptibilidade de cada indivíduo, a higiene do ambiente, o estresse a que a vaca está submetida, as diferentes cepas e espécies de microorganismos, com suas diferentes virulências; as estratégias de manejo, incluindo alimentação e funcionamento do equipamento de ordenha, procedimentos de ordenha com ênfase na questão da higiene, conscientização dos funcionários e outros fatores diversos, os quais devem ser considerados em programas de controle da doença (PHILPOT, 2002).

A doença apresenta-se na forma clínica ou subclínica. Na forma subclínica, não há mudanças visíveis no aspecto do leite ou do úbere (DIAS, 2007), mas caracteriza-se por alterações na composição do leite, tais como aumento na contagem de células somáticas (CCS), aumento nos teores de proteínas séricas; diminuição nos teores de caseína, lactose, gordura e cálcio do leite (PHILPOT; NICKERSON, 2002).

As infecções intramamárias são frequentes e importantes em bovinos leiteiros, sendo responsáveis por grandes prejuízos à pecuária leiteira pois ocasionam redução na produção de leite, gastos com

\footnotetext{
${ }^{1}$ Zootecnista, Mestre em Zootecnia.

${ }^{2}$ Médica Veterinária, Professora Dra do Curso de Zootecnia da Universidade Federal do Rio Grande do Norte.
} 
medicamentos e assistência veterinária, descarte de leite contaminado após tratamento e descarte precoce de animais doentes (COSTA et al, 1999).

A ocorrência da mastite subclínica sofre influência direta da estação do ano, onde em diversos trabalhos realizados, o aumento de casos de mastite subclínica foi verificado nos meses mais quentes do ano, ressaltando que as condições ambientais nesse período (temperatura e umidade alta) aumentam os fatores de risco para a ocorrência de novas infecções, as quais são as principais causas da elevação da CCS (SANTOS; FONSECA, 2005).

Nesse contexto, o presente trabalho teve por objetivo avaliar a incidência de casos de mastite subclínica em vacas lactantes da raça Girolanda nos períodos seco e chuvosos do ano, em uma propriedade na região do litoral do estado do Rio Grande do Norte.

\section{MATERIAL E MÉTODOS}

O presente estudo foi realizado em uma fazenda produtora de leite tipo "B", que consiste no leite integral quanto ao teor de gordura, refrigerado na propriedade e nela mantido pelo período máximo de $48 \mathrm{~h}$, em temperatura igual ou inferior a $4^{\circ} \mathrm{C}$, atingida no máximo $3 \mathrm{~h}$ após o término da ordenha, transportado para estabelecimento industrial, para processamento, apresentando, no momento do seu recebimento, temperatura igual ou inferior a $7^{\circ} \mathrm{C}$. A propriedade está localizada no município de São Gonçalo do Amarante, na Região Litoral do Estado do Rio Grande do Norte, nas coordenadas geográficas 5०47'36" latitude Sul e 35¹9'46" longitude Oeste.

Foram coletadas amostras mensais do leite, durante o período de novembro de 2005 a novembro de 2006, em todas as vacas da raça Girolanda em lactação (independente da idade, do número de lactação e do período de lactação), num total de 2599 animais e 9677 amostras. O número de vacas em lactação e de tetos produtivos avaliados, em cada mês encontram-se na Tabela 1. Excluiu-se das avaliações os tetos que apresentavam positivos ao teste da caneca de fundo preto, indicativo da mastite clínica. Os animais eram ordenhados mecanicamente, em duas ordenhas, pela manhã e à tarde.

TABELA 1. Número de vacas em lactação e de tetos produtivos avaliados, a cada mês, durante o período de estudo.

\begin{tabular}{llll}
\hline \multicolumn{1}{c}{ Mês } & Ano & Vacas & Tetos \\
\hline Novembro & 2005 & 225 & 841 \\
Dezembro & 2005 & 226 & 845 \\
Janeiro & 2006 & 236 & 898 \\
Fevereiro & 2006 & 246 & 934 \\
Março & 2006 & 212 & 807 \\
Abril & 2006 & 208 & 762 \\
Maio & 2006 & 216 & 773 \\
Junho & 2006 & 161 & 583 \\
Julho & 2006 & 177 & 654 \\
Agosto & 2006 & 161 & 600 \\
Setembro & 2006 & 177 & 667 \\
Outubro & 2006 & 177 & 670 \\
Novembro & 2006 & 177 & 643 \\
\hline
\end{tabular}


O diagnóstico da mastite subclínica foi feito através do "California Mastits Test" (CMT). A análise do leite foi realizada no momento da ordenha matutina, de acordo com a técnica de Schalm e Norlander (1957), após o pré dipping dos animais. Ao fim da ordenha das vacas o pós dipping era realizado.

Os dados de precipitação pluviométrica referentes ao período de 2005 e 2006 foram obtidos do Departamento de Meteorologia da Empresa de Pesquisa Agropecuária do Rio Grande do Norte, onde foi possível definir o período chuvoso (março a setembro) e o seco (outubro a fevereiro); a caracterização do regime pluviométrico da área de estudo encontra-se na Figura 1.

Figura 1. Precipitação pluviométrica da área, durante o período de estudo segundo o Departamento de Meteorologia da Empresa de Pesquisa Agropecuária do Rio Grande do Norte.

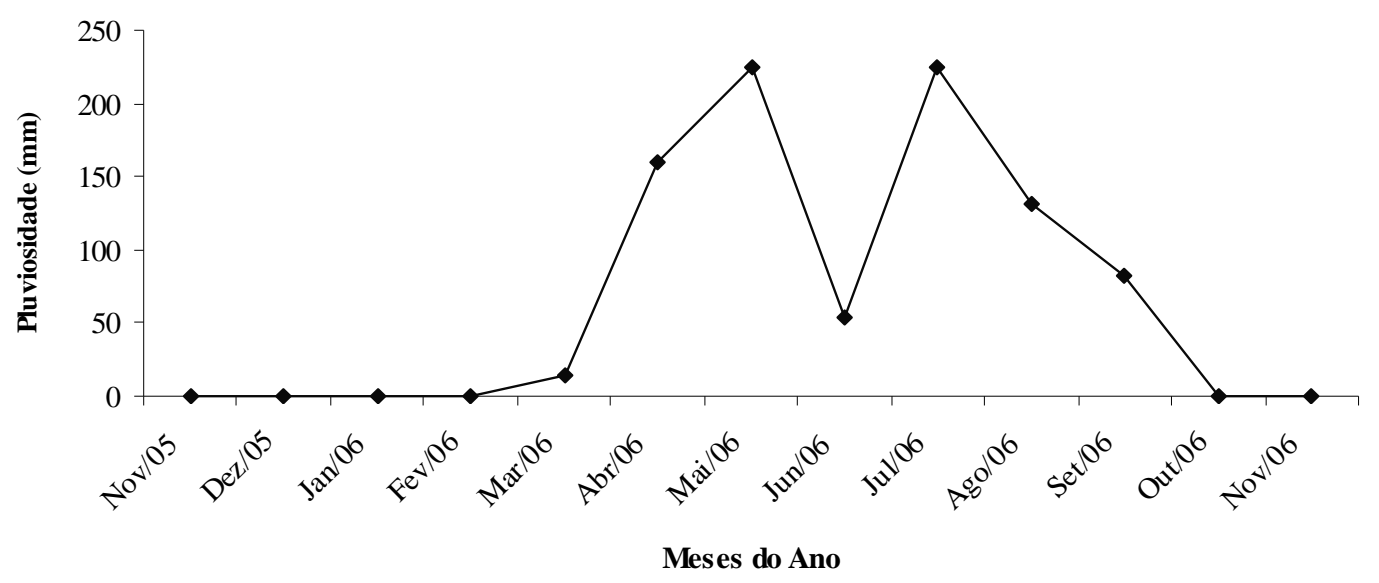

Os valores de mastite subclínica observados nos tetos e nos animais foram submetidos à análise de variância através do procedimento ANOVA. A comparação de médias foi feita através do teste Tukey, com nível de significância de 5\%. As análises foram realizadas utilizando o programa SAS (STATISTICAL ANALYSIS SYSTEM, 2000).

\section{RESULTADOS E DISCUSSÃO}

Os índices médios de mastite subclínica encontrados por vaca e por tetos, podem ser observados na Tabela 2.

TABELA 2- Valores de mastite subclínica por teto e por animal, nos diferentes períodos do ano, em fazenda produtora de leite tipo "B", no estado do Rio Grande do Norte.

\begin{tabular}{ccccc}
\hline \multirow{2}{*}{ Mastite Subclínica } & \multicolumn{2}{c}{ Período do ano } & P & CV (\%) \\
\cline { 2 - 3 } & \multicolumn{2}{c}{ Seco } & & \\
\hline Em tetos & $50,7 \mathrm{~b}$ & $59,8 \mathrm{a}$ & 0,0011 & 6,82 \\
Em animais & $76,0 \mathrm{a}$ & $81,6 \mathrm{a}$ & 0,0674 & 6,39 \\
\hline
\end{tabular}

Médias na linha seguidas de mesmas letras minúsculas não diferem entre si, pelo teste de Tukey $(\mathrm{P}>0,05)$. 
Observou-se efeito $(\mathrm{P}<0,05)$ dos períodos seco e chuvoso do ano sobre a ocorrência de mastite nos tetos dos animais. Maior incidência da doença foi verificado no período chuvoso do ano $(59,8 \%)$. A ocorrência de chuvas no período chuvoso aliado as altas temperaturas características da região avaliada durante todo o ano, podem ter contribuído para essa variação. Para Vianni et al (1992) na etiopatogenia da mastite, além dos agentes patogênicos, os componentes do clima, entre eles a temperatura e a umidade, têm grande importância na ocorrência da doença. Onde precipitações elevadas, aliadas à altas temperaturas, podem favorecer a uma maior incidência de casos de mastite subclínica (HARMON, 1994) pelo aumento da susceptibilidade do animal a infecções e ao número de patógenos aos quais os mesmos estariam expostos (SANTOS, 2004).

Os casos de mastite nos tetos (50 a 59\%) foram superiores aos verificados por Lins e Marreiros (1992), no estado do Piauí (21,94\%) e ao encontrado por Almeida; Silva (1998), no estado de Pernambuco $(19,80 \%)$. Valores de 44,88\% a 97,0\% são encontrados no Brasil, caracterizando a alta incidência da doença nos rebanhos do país (BRANT; FIGUEIREDO, 1994).

Martins et al (2006), ao analisarem a prevalência de mastite subclínica no rebanho de uma queijaria em Nossa Senhora do Livramento, MT, verificaram a presença da enfermidade em 74,2\% dos animais analisados. Costa et al (1995), ao examinar 2419 vacas Holandesas Preta e Branco e mestiças em diferentes estágios de lactação, nos Estados de São Paulo e Minas Gerais, encontraram a doença em $72,56 \%$ dos animais. Valores inferiores aos encontrados neste estudo para vacas com a doença (76 a $81 \%$ ).

A alta prevalência da mastite encontrada tanto no período chuvoso quanto no seco, para tetos e vacas, na propriedade, mostra a necessidade de se implantar um programa de controle da doença. Rupp et al (2000) afirma que o primeiro passo do programa é verificar o "status" de mastite do rebanho antes de qualquer alteração do manejo e que um dos pontos mais importantes no controle da mastite é conscientização dos produtores das perdas econômicas e educação sanitária dos tratadores e ordenhadores.Para Radostits et al (2002) dentro de um programa de controle da mastite, entre os pontos a serem considerados a imersão de tetos pré e pós-ordenha de todos os animais ordenhados com desinfetante germicida que não agrida a pele dos tetos, é de grande importância. Essa prática já estava presente no manejo dos animais, no entanto o uso do pós dipping, muitas vezes não é realizado de forma correta pelos produtores, sendo comuns falhas devido à escolha de produtos inadequados, má aplicação e descuido com a frequência de troca e remoção do produto (LARANJA; MACHADO, 1994), Além disso, os altos índices podem estar relacionados à higiene dos ordenhadores, baixa escolaridade, baixo nível de profissionalização, entre outras práticas (FERREIRA et al, 2007). Estes fatores podem justificar o alto percentual de tetos reagentes ao CMT encontrados neste trabalho. Sendo necessário o acompanhamento criterioso de todas as práticas realizadas nos animais, no momento da ordenha, para verificar as deficiências do manejo, permitindo então que um programa de controle da doença seja implantado.

\section{CONCLUSÃO}

O período do ano afetou a ocorrência de casos de mastite subclínica nas vacas, com maior incidência da doença durante o período chuvoso do ano. Ajustes no manejo da ordenha são necessários, especialmente no período chuvoso do ano.

\section{REFERÊNCIAS}

ALMEIDA, M. A. C.; SILVA, F. F. Prevalência de mastite subclínica em bovinos por Staphylococcus sp e Streptococcus sp na microrregião de Garanhuns. Ciência Veterinária Tropical, v.1, n.1, p.18-24, 1998. 
BRANT, M. C.; FIGUEIREDO, J. B. Prevalência da mastite subclínica e perdas de produção em vacas leiteiras. Arquivo Brasileiro de Medicina Veterinária e Zootecnia, v.46, p.595-606. 1994.

COLDEBELLA, A. Contagem de células somáticas e produção de leite em vacas holandesas confinadas. Piracicaba, 2003. 97f. Tese (Doutorado em Agronomia - Ciência Animal e Pastagens) Escola Superior de Agricultura "Luiz de Queiroz", USP.

COSTA, E. O.; MELVILLE, P. A.; RIBEIRO, A. R. Índices de mastite clínica e subclínica nos estados de São Paulo e Minas Gerais. Revista Brasileira de Medicina Veterinária, v.17, n.5, p.215-217, 1995.

COSTA, E. O.et al. Avaliação da terapia de mastite clínica: eficácia terapêutica medida em número de dias em tratamento. Revista Napgama, v.2, n.2, p.10-14, 1999.

DIAS, R. V. C. Principais métodos de diagnósticos e controle da mastite bovina. Acta Veterinária Brasílica, v.1, n.1, p.23-27, 2007.

FERREIRA, J. L.et al. Prevalência e etiologia da mastite bovina no município de Teresina, Piauí. Ciência Animal Brasileira, v.8, n.2, p.261-266, abr./jun. 2007.

FREITAS, M. F. L.et al. Perfil de sensibilidade antimicrobiana in vitro de Staphylococcus coagulase positivos isolados de leite de vacas com mastite no agreste do estado de Pernambuco. Arquivos do Instituto Biológico, v.72, n.2, p.171-177, 2005.

HARMON, R. J. Phisiology of mastitis and factors affecting somatic cell counts. Journal of Diary Science, v.77, n.7, p.2103-2112, 1994.

LARANJA, L. F.; MACHADO, P. F. Avaliação da efetividade de um programa de controle de mastite bovina em fazendas produtoras de leite B do estado de São Paulo. Scientia Agricola, v.51, n.2, p.569-577, 1994.

LEVISON, W.; JAWETZ, E. Microbiologia médica e imunologia. 4. ed. Porto Alegre: Artmed, 1998. $415 \mathrm{p}$.

LINS, J. L. F. H. A.; MARREIROS, V. P. N. Mamite bovina na bacia leiteira de Teresina, PI. IAvaliação do sistema de produção. II - Prevalência de mastite. III - Contribuição à análise epidemiológica. In: CONGRESSO INTERNACIONAL DE MEDICINA VETERINÁRIA EM LÍNGUA PORTUGUESA, 6, Anais... Salvador, BA, 1992. p.227-228.

MARTINS, R. P.et al. Etiologia da mastite subclínica em vacas do rebanho de uma queijaria em Nossa Senhora do Livramento, MT. Higiene Alimentar, v.20, n.139, p.104-409, 2006.

PHILPOT, W. N. Qualidade do leite e controle de mastite: passado, presente e futuro. In: CONGRESSO PANAMERICANO DE QUALIDADE DO LEITE E CONTROLE DE MASTITE, 2, Anais... São Paulo, SP, 2002. p.23-38.

PHILPOT, W. N.; NICKERSON, C. Vencendo a luta contra a mastite. Westfalia Surge. Naperville, IL: Ed. Milkbizz, 2002.

RADOSTITS, O. M., BLOOD D. C.; GAY, C. C. Clínica veterinária: um tratado de doenças dos bovinos, ovinos, suínos, caprinos e equinos. 9 ed. Rio de Janeiro: Guanabara Koogan, 2002. 1737 p.

RUPP, R.; BEAUDEAU, F.; BOICHARD, D. Relationship between milk somatic-cell counts in the first lactation and clinical mastitis occurrence in the second lactation of French Holstein cows. Preventive Veterinary Medicine, v.46, p.99-111, 2000.

SANTOS, M. V. O compromisso com a qualidade do leite no Brasil. Passo Fundo: Universidade de Passo Fundo, p.38-55, 2004. 
SANTOS, M. V.; FONSECA, L. F. L. Contagem de células somáticas: uma moderna ferramenta para controle de mastite e qualidade do leite, 2005. (Coleção gado de leite - Merial, Fascículo III).

SAS - STATISTICAL ANALYSIS SYSTEM INSTITUTE, Inc 2000. SAS user's guide: Statistic Vr., SAS, Cary, N. C., 2000.

SCHALM, O.W.; NOORLANDER, D.O. Eperiments and observations leading to development of Califórnia Mastitis Test. Journal of the American Veterinary Medical Association, n.130, p.199-204, 1957.

VIANNI, M. C. E.; NADER FILHO, A.; LANGENEGGER, J. Frequência de isolamento de Staphylococcus coagulase positiva e coagulase negativa na mastite subclínica em bovinos e sua influência na produção láctea. Arquivo da Universidade Federal Rural do Rio de Janeiro, v.15, n.2, p.187-192, 1992. 